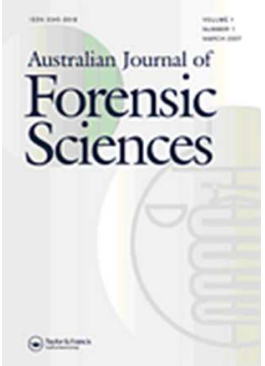

\title{
Culture is our business: Issues and challenges for forensic and correctional psychologists
}

\begin{tabular}{|r|l|}
\hline Journal: & Australian Journal of Forensic Sciences \\
\hline Manuscript ID & Draft \\
\hline Manuscript Type: & Plenary \\
\hline Keywords: & culture, indigenous, risk assessment, forensic psychology, cross-cultural \\
\hline & \\
\hline
\end{tabular}

\section{SCHOLARONE ${ }^{m}$}

Manuscripts 


\title{
Australian Journal of Forensic Sciences
}

\begin{abstract}
Psychology has made significant advances in the development of more empirical, standardised, and consistent approaches to the prediction, assessment, and treatment of offending behaviour. However, crime occurs in a cultural context. Similarly, forensic and correctional psychology derive from a cultural basis that privileges certain types of knowledge and promotes certain forms of practice that are incommensurate with the outlook and realities of some offenders and their communities. While there is an emerging literature on ethnicity and race in criminal justice psychology, very little research that addresses culture is published. The reasons for this knowledge gap are complex, not least because the worldviews of indigenous and diverse communities do not superimpose neatly onto current best-practice models of risk assessment or offender rehabilitation. Given Australia and New Zealand's commitment to the involvement and wellbeing of indigenous peoples as well as the shared experience of progressively more pluralistic societies, it is argued that there is a critical need to bring the somewhat disparate domains of forensic psychology and culture into conversation with a view to informing policy and practice. The example of risk assessment is used to illustrate some of the complexities of working with cultural difference. Central to this article is a call for a culturally-engaged and proactive philosophy of practice that embraces the needs of diverse offenders, victims, and communities.
\end{abstract}

Keywords: culture, indigenous, risk assessment, forensic psychology, cross-cultural 


\section{Australian Journal of Forensic Sciences}

\section{“'Culture Is Our Business'... 'Culture Is Our Business'... It can be said straight from the shoulder, with a thud: 'Culture Is Our Business'." 1}

It goes without saying that crime is the most central concept in the forensic sciences. Crime also occurs in a cultural context - as does forensic science - and nowhere is this more apparent than in the application of psychology in forensic and correctional settings. Offending behaviour, such as interpersonal aggression ${ }^{2}$ or sexual harm against children $^{3}$, is a global social problem that is neither limited to a particular geographical location nor a period in time. Indeed, prohibitions against specific criminal acts are so commonplace as to suggest a ubiquitous understanding of the multifaceted harms that can occur as a result of this behaviour. Psychology has made significant advances in understanding offending behaviour as a forensically-fruitful endeavour, especially the development of empirical and standardised approaches to the prediction, assessment, and treatment of violent and sexually harmful behaviour.

New Zealand and Australia are pluralistic countries, and as individuals travel across borders, the two nations have become increasingly diverse in ethnic composition.

Consequently, criminal justice professionals' engagement with culturally different offenders will inevitably become a routine component of forensic and correctional psychology practice. However, as it stands, the role of culture is neither widely-discussed, defined, nor understood in this space. For instance, a cursory perusal of the Web of Science a database revealed just over 2,500 papers featuring 'culture' as a key term in published forensic research since 1970. Until a fuller understanding emerges, the application of psychology in the forensic and correctional space has to accommodate for the issues related to cultural diversity as a central reality in the lives of offenders - and practitioners - as well as the communities with which they interact. While the boundaries of cultural difference extends beyond ethnicity and gender to include migrants and refugees, spiritual/religious communities and sexual orientation, this article briefly outlines the current status of forensic and correctional psychology as it relates to indigenous ${ }^{b}$ peoples in the criminal justice space and identifies some knowledge gaps and challenges for the field in the Australasian region, with particular emphasis on the scientist-practitioner domains of research and practice of psychological risk assessment.

\footnotetext{
a Search terms included: crim $^{*}$, offen*, forensic, and cultur*, was exclusive to articles in English and the top five discipline categories by record count (psychology, criminology, etc.).

${ }^{b}$ This is an ambiguous term to be fair, and not always congenial, but for the sake of brevity, I refer to 'indigenous' peoples as those who are typically a non-dominant group that have an acknowledged claim to be the original inhabitants of a given land. In this context, New Zealand Maori and peoples from Aboriginal and Torres Strait Island communities.
} 


\section{Australian Journal of Forensic Sciences}

\section{The scope of forensic psychology in Australia and New Zealand}

While no consensual universal definition of 'forensic psychology' exists ${ }^{4}$, the range of roles that psychologists occupy in psycho-legal contexts varies depending upon the legislative constraints and the appropriate application of psychology across diverse jurisdictions. The scope for psychologists whose practice interacts with, or is embedded within, the criminal justice systems in Australasia involves a number of roles typical of other psychologists, such as assessment, treatment, supervision, advice, and research, but that occur in specialised settings, such as prisons, probation sites, Courts, and forensic institutions. The Australian Psychological Society ${ }^{5}$ frames the practice context of forensic psychologists as that of scientist-practitioners who "apply psychological knowledge, theory and skills to the understanding and functioning of legal and criminal justice systems, and to conducting research in relevant areas" such as Courts and other tribunals, mental health services (general and forensic), corrections, child protection, family services (e.g., family violence counselling services, parent training programs), alcohol and other drug rehabilitation services, police, research (i.e., academia and policy), and private practice.

While there is no forensic division of psychology as such in New Zealand, the Department of Corrections employs the largest number of psychologists working with individuals involved in the criminal justice system followed by the regional forensic mental health services or non-government organisations. Like the Australian corrections agencies, New Zealand have adopted the Canadian model of offender management that emphasises principles of (1) allocating resources to the most immanent and hazardous individuals that present the greatest risk to the community, (2) targeting those changeable factors, or needs, that have an empirical relationship to recidivism and the addressing of which will impact on the likelihood and severity of reoffending, and (3) delivering rehabilitation interventions and programmes that reflect responsivity to characteristics that offenders present with (e.g., cognitive capacity, degree of literacy, emotional stability, culture $)^{6}$. These principles inform decision-making for large volumes of offenders where resources are limited or scarce with a view towards reducing recidivism and, in turn, promoting safer communities. The routine activities of dangerousness prediction and offender rehabilitation are derived from - and inform - these principles.

\section{Risk assessment: A core forensic psychology activity}

One of the critical tasks for forensic psychologists is assisting decision-making bodies, such as the Courts and parole board to determine the likelihood of future offending behaviour, the degree of dangerousness that a given offender may present, and to whom. Although discussed more fully elsewhere ${ }^{7}$, the assessment of risk of recidivism can be seen as a formal process of information-gathering and synthesis that is concerned with two 


\section{Australian Journal of Forensic Sciences}

primary outcomes, namely (1) how accurately criminal behaviour can be predicted in an individual case, and (2) how to best classify a given offender into appropriate subgroups in order to assign them to particular interventions ${ }^{6}$. In order to optimise the delicate trade-off between potentially hazardous offenders and essential resources, the judicious application of psychological science is prioritised, not least because of the empirical basis of this knowledge and the amenability of psychological approaches to measurement and evaluation of effectiveness, which facilitates data-centric practices as part of offender management. Accordingly, Conroy and Murrie ${ }^{9}$ summarise the central tasks and questions in formal risk assessments as involving: (1) definition of the referral question (risk of what?), (2) consideration of normative data and population base rates (what is known overall?), (3) consideration of empirically-supported risk and protective factors (what is known about individuals similar to this one?), (4) consideration of idiographic factors (what is known about this individual?), and (5) communication of risk (what can be said about the results?). While there may be an intuitive logic to this process, the literature has yielded a number of factors that reliably relate to recidivism - albeit with some variance. Table 1 displays a number of risk factors as assessed across some commonly used structured professional judgment (SPJ) tools. As can be seen, many of these factors have an obvious cultural salience that relies on interpretations of social behaviour (e.g., non-compliance, negative peers, and negative attitudes towards authority) or internal cognitive-affective states (e.g., suicidal/homicidal ideation, negative attitude towards interventions, mental illness, and cognitive distortions) that require a culturally-informed interpretation. Also apparent in this Table is a general shift towards recognising stable (i.e., changeable but durable) risk factors over time. For some Maori and Aboriginal and Torres Strait Island offenders, the common experience of racism and other negative stereotyping, as well as close social networks with similarly disadvantaged others, can promote lifestyle choices such as gang involvement, which in turn can promote violence, substance abuse, and negative and/or untrusting attitudes towards social institutions such as the Police ${ }^{10}$. 
Australian Journal of Forensic Sciences

Table 1

Risk Items across Commonly-used SPJ Tools.

\begin{tabular}{|c|c|c|c|c|c|c|}
\hline \multirow[b]{2}{*}{ Assessment variable } & \multicolumn{6}{|c|}{$\begin{array}{c}\text { SPJ guide } \\
\text { (Year of initial publication/dissemination) }\end{array}$} \\
\hline & $\begin{array}{l}\text { SVR-20 } \\
(1997)^{11}\end{array}$ & $\begin{array}{c}\text { SARA } \\
(1999)^{12}\end{array}$ & $\begin{array}{c}\text { VRS } \\
(2000)^{13}\end{array}$ & $\begin{array}{l}\text { HCR-20 } \\
(2001)^{1415}\end{array}$ & $\begin{array}{c}\text { DRAOR } \\
(2008)^{1617}\end{array}$ & $\begin{array}{l}\text { SAPROF } \\
(2009)^{18}\end{array}$ \\
\hline \multicolumn{7}{|l|}{ Acute risk factors } \\
\hline Suicidal ideation & $\checkmark$ & $\checkmark$ & & & & \\
\hline Homicidal ideation & $\checkmark$ & $\checkmark$ & & & & \\
\hline Substance use & $\checkmark$ & $\checkmark$ & $\checkmark$ & & & \\
\hline $\begin{array}{l}\text { Exposure } \\
\text { destabilisers }\end{array}$ & & & $\checkmark$ & $\checkmark$ & & \\
\hline $\begin{array}{l}\text { Stress/Negative } \\
\text { mood }\end{array}$ & & & $\checkmark$ & $\checkmark$ & $\checkmark$ & $\checkmark$ \\
\hline Interpersonal aggn & & $\checkmark$ & $\checkmark$ & & $\checkmark$ & $\checkmark$ \\
\hline \multicolumn{7}{|l|}{ Stable risk factors } \\
\hline $\begin{array}{l}\text { Negative attitude: } \\
\text { Authority }\end{array}$ & & & $\checkmark$ & $\checkmark$ & $\checkmark$ & $\checkmark$ \\
\hline Intervention & $\checkmark$ & & & $\checkmark$ & & \\
\hline Non-compliance & & & $\checkmark$ & $\checkmark$ & & \\
\hline Negative peers & & & $\checkmark$ & & $\checkmark$ & $\checkmark$ \\
\hline Major mental illness & $\checkmark$ & $\checkmark$ & $\checkmark$ & $\checkmark$ & & \\
\hline Antisocial personality: & $\checkmark$ & & $\checkmark$ & & & \\
\hline Impulsivity & & $\checkmark$ & $\checkmark$ & $\checkmark$ & & \\
\hline Entitlement & & & $\checkmark$ & & $\checkmark$ & $\checkmark$ \\
\hline Poor attachments & & & $\checkmark$ & & $\checkmark$ & $\checkmark$ \\
\hline $\begin{array}{l}\text { Cognitive } \\
\text { distortions }\end{array}$ & & & $\checkmark$ & & $\checkmark$ & $\checkmark$ \\
\hline Lack of insight & $\checkmark$ & & $\checkmark$ & & & \\
\hline Poor problem-solving & & & $\checkmark$ & & $\checkmark$ & $\checkmark$ \\
\hline
\end{tabular}

Similarly, Table 2 shows items that reflect protective factors, or those aspects of a given offender's life context that has some empirical relationship with the reduction of offending behaviour across the same measures. These items rely on interpretations of social behaviour (including relationships with authority), recognition of identity, and adaptiveness of lifestyle choices. Arguably, protective factors, as currently assessed, would necessitate cultural knowledge of the offender's community and culture in order to understand if and how a lifestyle component would have a protective function. For instance, good financial 


\section{Australian Journal of Forensic Sciences}

management abilities are essential life skills especially for individuals who are too accustomed to extreme disadvantage and deprivation.

Table 2

Protective Factors across Commonly-used SPJ Tools.

\begin{tabular}{|c|c|c|c|c|c|c|}
\hline \multirow[b]{2}{*}{ Assessment variable } & \multicolumn{6}{|c|}{$\begin{array}{c}\text { SPJ guide } \\
\text { (Year of initial publication/dissemination) }\end{array}$} \\
\hline & $\begin{array}{l}\text { SVR-20 } \\
(1997)\end{array}$ & $\begin{array}{l}\text { SARA } \\
(1999) \\
\end{array}$ & $\begin{array}{l}\text { VRS } \\
(2000) \\
\end{array}$ & $\begin{array}{l}\text { HCR-20 } \\
(2001)\end{array}$ & $\begin{array}{l}\text { DRAOR } \\
(2008) \\
\end{array}$ & $\begin{array}{l}\text { SAPROF } \\
(2009)\end{array}$ \\
\hline $\begin{array}{c}\text { Positive attitude: } \\
\text { Authority }\end{array}$ & & & $\checkmark$ & & & $\checkmark$ \\
\hline Intervention & & & $\checkmark$ & & & $\checkmark$ \\
\hline Prospects & & & & & $\checkmark$ & $\checkmark$ \\
\hline \multicolumn{7}{|l|}{ Prosocial orientation: } \\
\hline Identity & & & & & $\checkmark$ & $\checkmark$ \\
\hline Support network & & & $\checkmark$ & & $\checkmark$ & $\checkmark$ \\
\hline Social control & & & & & $\checkmark$ & $\checkmark$ \\
\hline \multicolumn{7}{|l|}{ Lifestyle: } \\
\hline Work ethic & & & $\checkmark$ & & & $\checkmark$ \\
\hline Leisure activities & & & $\checkmark$ & & & $\checkmark$ \\
\hline Intimate relationship & & & $\checkmark$ & & & $\checkmark$ \\
\hline Financial mgt & & & $\checkmark$ & & & $\checkmark$ \\
\hline Medical adherence & & & $\checkmark$ & & & $\checkmark$ \\
\hline \multicolumn{7}{|l|}{ Personality attributes: } \\
\hline Empathic & & & $\checkmark$ & & & $\checkmark$ \\
\hline Intelligence (high) & & & $\checkmark$ & & & $\checkmark$ \\
\hline Secure attachment & & & $\checkmark$ & & & $\checkmark$ \\
\hline Coping/Prob. solve & & & $\checkmark$ & & $\checkmark$ & $\checkmark$ \\
\hline
\end{tabular}

In sum, background factors are of fundamental importance - especially if that background is characterised by poverty, disadvantage and negative stereotypes ${ }^{19}$. Offending behaviour is defined in legal terms, but occurs in a cultural context that is both informed by, and a violation of, networks of shared social meanings - contested social and cultural processes by which situations are defined, persons and groups are categorized, and consequences for people are understood - that otherwise influence an individual's perception of their behaviour and the impact it has on others ${ }^{20}{ }^{21}$. In Western societies, offending behaviour is regarded in a quasi-medicalised light and seen through a lens that shapes professional perceptions and experiences of criminal justice concerns in 


\section{Australian Journal of Forensic Sciences}

psychological ways. For instance, risk assessment, perhaps more than any other form of psychological encounter, reflects a significant power relationship between an individual offender and a practitioner, not least because of its stated purpose of providing the basis for informing case management decisions, the consequences of which will have a long-standing impact for offenders. The convergence of ethnicity, socioeconomic status, and culture can result in unique legal issues that have a far-reaching impact on almost every aspect of their lives, such as (1) being without (legitimate) means, (2) racial discrimination (non-dominant culture), and (3) actual or perceived membership in criminal communities (e.g., gangs). These issues are unavoidable challenges for forensic and correctional psychologists who work with indigenous offenders. The following section discusses foreseeable challenges in practice.

\section{Practice challenges}

There are few clear-cut indicators of 'success' when working with cultural difference. Having said that, there is an imperative for forensic practitioners to recognise the limitations of risk assessment tools with non-normative groups and the ethical practice when working with cultural difference.

In recent years, the forensic and criminal justice psychology literature has been largely silent on the issue of culture. Both race (an imposed classification based on genetically-imposed phenotypic characteristics) and ethnicity (social group with shared history/ancestry) have been used as organizing principles in this research area and have offered a convenient demarcation strategy to describe a sample ${ }^{22}{ }^{23}$. However, culture, by contrast, is a more complicated concept and reflects the interaction between the social world and people's ideas about it ${ }^{24}$. Broadly speaking, culture is something that is learned and shared amongst a community and includes ideas of how to code and interpret the environment and events, recognise and decide what is valued or rejected, what activities should be enacted or prohibited, and processes of how to define and solve problems ${ }^{25}$. In this regard, culture is best appreciated in a context of time-dependent relationships to be recognised rather than as a 'thing' to be reified and measured. Offending behaviour, then, is likely to be more fully understood when the offender's cultural context is considered especially those who face multiple prejudices such as criminal histories, lower socioeconomic status, and membership in an ethnic minority community.

The recent decision of Ewert $v$. Canada ${ }^{27}$ raised critical concerns about the supposed cross-cultural generalisability of some risk assessment tools that had not been validated across different cultural groups. The plaintiff, Jeffrey Ewert, was a 53-year old Métis prisoner serving two life sentences for second degree murder and attempted murder as well as 15 months imprisonment for an escape from lawful custody (i.e., over 30 years in 


\section{Australian Journal of Forensic Sciences}

federal correctional facilities). Ewert alleged that the psychological risk assessment tools used by Correctional Service of Canada were not culturally appropriate for use with Aboriginal prisoners. The ensuing debate between expert witnesses centred on the presumed legitimacy of the psychological assessment tests used in this case. The expert witness for Ewert delivered evidence to show that the assessment tools were prone to various forms of cultural bias and supported the non-use of the scores of the assessment tests of Aboriginal prisoners because of the cultural differences between Aboriginal and nonAboriginal groups in Canada. Subsequently, the Court determined that Ewert was successful in proving that the assessment tests were unreliable due their susceptibility of cultural bias.

Furthermore, the Court found that the results of the tests adversely impacted Ewert by elevating his security classification and reducing his desire to apply for parole.

The case of Ewert $v$. Canada highlights one of the unique challenges faced by forensic psychologists who work in correctional contexts and encounter offenders who are not only culturally different, but also have a special political status. Most current risk screening and classification tools have been validated with data from dominant culture (male) samples and the ability of these tools to accurately predict recidivism in other cultural groups remains largely unexamined. This issue has been raised with the Static-99, the most commonly used and the most widely researched measure to assess risk of sexual reoffending $^{28}$. This measure has also consistently shown a moderate level of predictive accuracy for sexual re-offending. However, differences have also been noted within subsets of the sex offender samples that have been studied. For instance, a Norwegian study ${ }^{29}$ found that the Static-99 predicted recidivism among Nordic and non-Nordic Europeans, but not among the African/Asian offenders in a Swedish national sample. In Australia ${ }^{30}$, poorer predictive validity (AUC $=.65$ ) was reported for Aboriginal and Torres Strait Island offenders assessed using another actuarial tool (the RRASOR) than for non-indigenous sexual offenders (AUC of .74), as did a study by Smallbone and Rallings ${ }^{31}$ for sexual (AUC $=.82$ vs .76), non-sexual violent ( $A \cup C=.64$ vs. .59$)$, and any violent recidivism $(A \cup C=.77$ vs. .67). In addition, a Canadian study of the Static-99-R and Static-2002-R involving five independent samples also reported a number of significant differences between Aboriginal and non-Aboriginal sexual offenders ${ }^{32}$. Aboriginal sexual offenders scored significantly higher than non-Aboriginal sexual offenders on total scores and items related to general criminality, whilst scoring lower on items related to sexual deviancy. These studies suggest that some instruments are less accurate when used with indigenous and other ethnic groups that have not been part of the normative samples for those measures and the need for local validation with sub-populations of offenders is imperative.

The core challenge for psychologists who conduct these assessments involves short-term 'stop-gap' estimations and have to rely 'best guesses' about what to do when 


\section{Australian Journal of Forensic Sciences}

asked to assess individuals from groups for whom limited validation data is available. However, reservations about the use of risk assessment tools with indigenous offenders go beyond those associated with problems of a lack of local validation data to include the possibility that current tools overlook important causes of offending in indigenous communities and, by doing so, fail to discern the interactions between key drivers of crime such as identity, cultural connectedness, mental illness, and substance abuse ${ }^{33}{ }^{34}$. An alternative view ${ }^{35}$ indicates a need to replace the 'risk factor approach' which emphasises aggregate correlates of crime with a more holistic and sensitive methodology that considers the underlying causes of their over-representation, including social and economic marginalisation grounded in historical processes.

Establishing a place for culture can be problematic in psychological practices such as risk assessment, not least because this is a domain of inquiry that utilises and values rule-governed assessment procedures and reliance on simplified and reductionistic understandings of group data. A typical risk assessment procedure is likely to draw upon a range of sources that are culturally-informed, such as an individual's historical context, psychiatric and medical condition, developmental history, current social context (including socioeconomic status), substance use, and family history. Furthermore, individuals often identify with multiple cultural realities. For example, offenders from communities that have experienced oppression from, and assimilation with, the dominant group may express an affinity for both their traditional people as well as the imposed norms of the dominant culture. To omit cultural information is to superficially treat an individual's reality.

The importance of culture in forensic psychology practice is also manifest in (1) responsibility of care, (2) informing decision-making, and (3) illuminating complexity, and is discussed as follows.

\section{Ethical responsibility of care}

Professional psychological associations in Western countries have recognised and affirmed respect for cultural diversity as an ethical responsibility. Consequently, ethical codes for psychologists include comment that those who perform risk assessments with populations that are not only ethnically different, but also culturally complex, need to acknowledge the limitations of any standard risk assessment instrument as applied to a particular population. In particular, ethical principles of respect and dignity for people and persons $^{363738}$, self-determination ${ }^{39}$, and interpreting assessment results ${ }^{40}$.

Apart from a shared philosophy of offender management across the criminal justice sectors in their respective jurisdictions, Australia and New Zealand also have the shared experience of recent colonization and the over-representation of indigenous peoples in prison. For instance, prisoners who claim (or are assumed) ancestry from Aboriginal or 


\section{Australian Journal of Forensic Sciences}

Torres Strait Island communities make up approximately $27 \%$ of the total prisoner population $(\mathrm{N}=36,100 \text { approx. })^{41}$ compared with $3 \%$ of the general population ${ }^{42}$. Whereas in New Zealand, Maori offenders who are imprisoned constitute $51 \%$ of the total prisoner population ${ }^{43}$ compared with $15 \%$ of the general population ${ }^{44}$. However, the proportion of psychologists (clinical and/or forensic) is woefully under-represented in both countries with $3.7 \%(n=38)^{45}$ of current practicing Maori psychologists and $0.4 \%(n=81)^{46}$ of psychologists descend from Aboriginal and Torres Strait Island communities - and not all of whom would necessarily be working in the forensic or criminal justice arena. As can be seen, the human resource that is most likely to possess a commensurate cultural understanding, if not a sense of cultural empathy, with a significant proportion of prisoners is disproportionate. It would be a gross generalisation to suggest that more indigenous psychologists need to be trained on the basis of numbers alone. However, it would behove agencies and organisations that employ or serve the psychology community to consider creative approaches to developing sustainable cultural capital and inviting members of indigenous communities to participate in the profession - or at least discussions with the profession to help shape a more Just agenda for practice.

\section{Culture informs decision-making}

Psychologists who practice in criminal justice settings seek to justify techniques, approaches, opinions, and recommendations on ethical and empirical grounds. It is recognised that psychologists generally (1) require reasonable scientific certainty, (2) make decisions on the basis of information that is imperfect and incomplete, (3) present findings in an accurate, organised, and easily-understood format, and (4) exercise competence in assessment techniques7. The activities of forensic and correctional psychologists in Australasia derive from a cultural basis that privileges certain types of knowledge and promotes certain forms of practice that can be incommensurate with the outlook and realities of some offenders and their communities.

An uncritical application of psychological assessment and rehabilitation practices, especially those that were developed in a different cultural context, risks an over-reliance on formal tools and therapeutic interventions that may criminalise extraordinary experience and deny the meaning-oriented subjectivity of offending in favour of classifying by risk band (e.g., 'high', 'moderate', 'low') that lacks personal and collective significance. Culture shapes what behaviours one expresses and how they are expressed, influences the meaning that an individual attributes to their offending behaviour, and how one interacts with the criminal justice system (e.g., mistrust, suspicion ${ }^{47}$ ). Culture also influences what a community regards as appropriate or inappropriate behaviour and what forms of social influence and control can effectively exert a powerful impact on an individual's likelihood of future antisocial 


\section{Australian Journal of Forensic Sciences}

behaviour. Culturally-informed beliefs, attitudes, and behaviours vary from group to group, with some communities reflecting greater tolerance for criminally deviant behaviour. For instance, Stermac and colleagues ${ }^{3}$ emphasised the role of social attitudes and beliefs as a source of cultural variability with sex offenders, particularly communities that have a different view of, or even a relatively high tolerance for, sexually harmful behaviour (e.g., genital touching). On the other hand, some communities have adopted more punitive approaches in the wake of egregious examples of offending (e.g., Sexually Violent Predator statutes ${ }^{48}$ ).

\section{Culture implies complexity}

Culture is subject to oversimplification - not least due to overly-broad and simplistic labels that obscure variation and unique differences within ethnocultural communities or via 'either/or' categorisations (e.g., high acculturation vs. deculturation) as though these distinctions were accurate and reflected meaningful representations of how people live in their communities ${ }^{49}$. Current risk assessment tools are not designed to handle cultural information. A function of this process is to decrease uncertainty of future offending by reducing the complexity of a wide array of data. This is largely achievable with sizable data sets that include only easily-measurable variables that are amenable to statistical analyses. Such prescriptive approaches risk minimizing or even neglecting cultural differences which are not as conducive to statistical measurement and inference as more concrete variables (e.g., age, number of prior convictions), and overlook 'realities' that are different from that of the practitioner.

Risk assessment measures also tend to be 'practitioner-oriented', rather than enduser-oriented, as they are developed by test designers who are also typically service providers and have a vested interest in, or even a belief in the 'goodness' of the assessment process rather than end-users like parole boards who consume the findings or the wider communities who are impacted by them. Such practices risk promoting a mythic ideal - often couched in terms of 'best practice' - where a belief exists in a single best and 'right way' of doing things. Furthermore, this perception reinforces a view that there is a unitary approach to risk assessments that should be practiced and readily dismisses alternative viewpoints, thus reducing the relevancy of risk assessments with culturally-different offenders and communities, especially those who hold a holistic worldview that embraces 'messy' concepts and have a high tolerance for ambiguity.

A central challenge, then, for any psychological assessment is to understand individuals in their context. To take steps to appreciate the perspective of individuals who are culturally different is to attempt to understand an alternative and collective worldview - a communal history ${ }^{5051} 52$. The impact of an individual's cultural heritage and socio-political legacy can inform the perpetration (and victimisation) of offending amongst specific 


\section{Australian Journal of Forensic Sciences}

communities. Aboriginal sex offenders in Canada were described ${ }^{53}$ as being more likely than non-Aboriginal sex offenders to exhibit issues associated with displacement, abandonment, and racism; personal identity confusion; history of maltreatment; poverty and death due to illness, suicide, and violence; deficits in education, employment skills, financial position, and social supports; and, histories of more aggressive sexual behaviours, suggesting a range of pervasive stressors that can impact on attitudes and interactions towards others that can be manifest across a population. An appreciation of the experience of these conditions can assist with fairer assessment practices.

\section{Cultural responsiveness}

The ethical principles of 'responsible caring' and 'social justice' means that psychologists have a duty to be culturally competent ${ }^{54}$. This is of specific importance because we know very little about how culture affects offending, change, or desistance. We do know that cultural differences can present barriers to contributing to psychological assessments or participating in rehabilitation programmes. For instance, stigmatizing nature of intervention programmes (especially disclosure-based treatment, where shame and shame management can present as responsivity barriers). Access to appropriate cultural advice can facilitate greater nuanced understandings of a given offender's needs, but 'expertise' in culture is often difficult to acquire. Many experts or holders of cultural knowledge can be mistrustful or sensitive to exploitation, do not communicate with outsiders, or do not necessarily understand what psychologists do. Further, a discrepancy in the philosophy of offender management between indigenous communities and government agencies can contribute to impaired relationships between parties when the agenda differs such as promoting wellbeing or reducing recidivism ${ }^{55}$. Also, as observed in Maori justice efforts in the late $20^{\text {th }}$ Century, collaborative efforts had difficult legacies due to a lack of structural support for Maori organisations to accommodate or the partnership with criminal justice agencies, inadequate consultation with stakeholder tribal groups, and/or a limited or different understanding of offence risk on the part of indigenous community partners ${ }^{56}$

The reasons for knowledge, and by extension - practice, gaps are complex, the worldviews of indigenous and diverse communities do not superimpose neatly onto current best-practice models of risk assessment or offender rehabilitation.

\section{Research issues}

Forensic psychology practices are informed by the scholarly empirical literature. However, the notable lack of published locally-derived culturally-informed research in Australasia has meant an over-reliance on imported knowledge, which in turn, promotes a universalist perspective that steers the academic narrative, which is currently concerned with 


\section{Australian Journal of Forensic Sciences}

two primary foci: accurate risk prediction (validity/reliability) and efficacious rehabilitation (conformity/sustainability). This section identifies research issues as they impact on the generation of knowledge and the prioritisation of outcomes and the legitimisation of practices.

\section{Knowledge: Indigenous v. empirical}

Crimes involve behaviours that are legally defined. However, legal definitions are far from being scientific concepts ${ }^{57}$. There is an emerging literature on ethnicity and race in criminal justice psychology (e.g., Journal of Ethnicity in Criminal Justice), but very little research that addresses culture is published. What counts as knowledge and whether it is reliable and valid is a core issue across forensic sciences and determines what is considered 'science' and 'non-science ${ }^{, 58}$. For instance, Western scientific approaches are more likely to be valued as evidenced by State-sponsored research and development than are other ideas that may be seen as 'exotic' and not derived from an empirical basis. This bias against the development of indigenous or minority-led research may reflect a selective reinforcement of scientific principles ${ }^{59}$ and can result in poor opportunities for indigenous-led researchers. Madison ${ }^{60}$ comments that a lack of publishing which is too-often the case in indigenous research means that there is a lack of 'interpretive community', that in turn means there is a lack of studies and models on the topic, which shapes content, form, and meaning in the literature.

Additionally, cultural knowledge, especially of indigenous peoples, is 'difficult knowledge' - in two senses. Firstly, indigenous knowledge does not superimpose or merge easily with quasi-medical conceptualisations of crime and desistance. Indeed, cultural knowledge adds another 'language' for practitioners to navigate. This is in addition to the psychological language of behaviour, the legal language of crime and offending, the statistical language of risk, the institutional language of security classification and/or sentence conditions, the imported psychotherapeutic language of rehabilitation, followed by translating this into plain language for end-users such as the offenders themselves, their families, and even the community at large.

Secondly, indigenous knowledge is 'difficult knowledge' in the sense that it is embedded in legacies of trauma that is a downstream effect of colonisation, oppression, dislocation, deprivation, and disadvantage. As such, encountering this knowledge requires 'care' - understanding such knowledge is a process of engagement rather than a quantifiable product ${ }^{61}$. Such information can also prompt feelings aversive to practitioners who position themselves as part of the dominant culture, like collective guilt or white privilege $^{62}$ that can drive potentially open and constructive dialogue about cultural differences underground. 


\section{Australian Journal of Forensic Sciences}

In short, culture is 'messy'. 'Culture' is difficult to measure, which means it is difficult to research, and by extension, difficult to absorb into practice in the same way one might adopt a new risk measure or therapeutic procedure. Furthermore, social systems are open and complex, and it can be difficult to isolate components of interest under controlled conditions as may occur in the natural sciences ${ }^{63}$. Whereas empirical knowledge is concerned with laws, cultural observation and engagement demands an interpretive focus in order to elicit meaning.

\section{Practices: Prioritised v. privileged}

The use of actuarial tools of risk prediction is an essential and routine component of risk assessment practice, reflecting a conclusion made by Quinsey, Harris, Hart, and Cormier's ${ }^{64}$ conclusion that actuarial methods are 'too good and clinical judgement too poor to risk contaminating the former with the latter'. The popularity of risk assessment instruments across international jurisdictions reflects the value that such tools have in facilitating offender management solutions. Instruments such as the Static-99 have enjoyed routine use beyond its country of development and has surfaced in such distant countries including Australia ${ }^{65}$ and New Zealand ${ }^{66}$. However, although a measure may demonstrate an acceptable level of validity during construction, it does not necessarily follow that it will also be valid for a specific individual in a specific situation ${ }^{67}$. Accordingly, practitioners are cautioned about the wholesale adoption of risk assessment tools that are used in jurisdictions and with cultural groups where these measures were not developed ${ }^{68} 69$.

Bonta $^{70}$ argued that useful and effective risk assessment measures are quantitative, structured, and empirically-linked to a relevant criterion as expressed by discrete events such as recidivism or parole failure. The benefits of quantitative methodologies serve to (1) reduce the complexity of data and increase empirical rigour, (2) demand structured protocols that reduce human error (and presumably bias) by means of strict scoring rules and systematic data-collection strategies, and (3) rely on specific criteria that reduces the range and type of outcomes of concern. Together, these aspects of instrument development reflect an increased focus on risk management as defined by specified results, but may also occlude related but competing interests that concern communities such as improving wellbeing or eliciting offender redemption narratives ${ }^{71}$.

Actuarial methods also assume an atheoretical and impersonal and culture-neutral basis that relies on 'factual' information such as that derived from official criminal records rather than data derived from subjective and less rigorous approaches. However, despite the impressive predictive accuracy of some of these measures, it is noted that the data itself is decontextualised. There is a claimed value-neutral and objective status of actuarial tools, but they lack context and base predictions on a small number of quantifiable variables. 


\section{Australian Journal of Forensic Sciences}

Culture, on the other hand, is context-specific and incommensurate with pure actuarial approaches because culture is meaningless in the absence of context.

Furthermore, actuarial and SPJ tools privilege data and apparent 'facts' that retreat from knowledge that results from regional inequities. In this sense, expert knowledge ('top down') takes precedence over local knowledge ('bottom up') as valuable or 'expert' in its own right. Risk tools are also somewhat anti-democratic in that they are devised as a result of differential access to data and technology (hardware, software, 'humanware', and data). Communities tend to have no ownership of this data - albeit not without reasons (privacy, etc.). Public dialogue about the ethical and responsible uses of these tools - especially of sentencing and sentence-related decisions are being made on the back of these. Indeed, there is a need for a forum where issues, information, alternative perspectives and decisions can be discussed in an open dialogue with a relevant public.

Lastly, the reduction of recidivism is a near-universal outcome that is aspired to across jurisdictions. However, alternative objectives such as 'improving wellbeing' is also a goal sought by indigenous communities that does not necessarily superimpose neatly onto

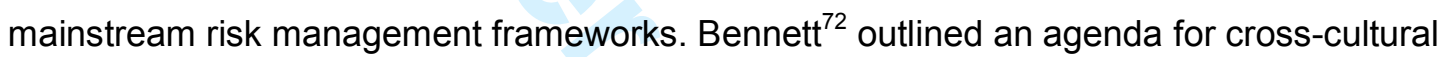
comparison research where the emphasis is on determining those variables that have a relationship with crime in at least two different cultural groups. If such a relationship exists, then the theory is evaluated as being generalizable. This kind of theorizing is possible when working with (1) discrete concrete quantitative variables, (2) constructs that have similar meanings across cultures, and (3) specifications of what conditions the model is true and useful. Failure to do so may lead to an invalid model and incorrect or misleading inferences. Furthermore, the language of psychology is attached to science that is primarily atomistic so individuals are seen as 'self-contained' and independent rather than relational or as an integral part of social systems. As such, the focus concern becomes one of causes and explanations (and cures?) rather than context. Culture, especially if characterised by holistic attitudes to reality, challenge psychologists claims to (1) objectivity, (2) independence, (3) neutrality, and (4) verifiability. In any case, forensic researchers must be alert to the possibility that research findings may be used to justify the implementation of social policies that further marginalise vulnerable populations.

In conclusion, risk assessment represents, in essence, a cultural practice that typically reflects and privileges an individualised Western cultural perspective over the realities of peoples from indigenous communities. Engaging culture is critical because it offers insights in defining relevant and meaningful outcomes for offenders and communities, determining the suitability and effectiveness of interventions, and (3) reintegration informing reintegration, especially how control in a given social group - especially one that is presumed to exert an influence on an offender - is defined and exercised. 


\section{Australian Journal of Forensic Sciences}

Given Australia and New Zealand's commitment to the involvement and wellbeing of indigenous peoples as well as the shared experience of progressively more pluralistic societies, it is argued that there is a critical need to bring forensic psychology and culture into conversation with a view to informing policy and practice. This article is a call for a culturally-engaged and proactive philosophy of practice that embraces the needs of diverse offenders, victims, and communities.

\section{References}

${ }_{2}^{1}$ McLuhan M. Culture is our business. New York (NY): McGraw-Hill; 1970. p. 8.

${ }^{2}$ Mitis F, Sethi D. Male-on-male violence: A leading cause of death around the world. In Donelly PD, Ward CL, editors. Oxford textbook of violence prevention: Epidemiology, evidence, and policy. Oxford (UK): Oxford University Press; 2015. pp. 57-63.

${ }^{3}$ Stermac LE, Segal ZV, Gillis R. Social and cultural factors in sexual assault. In Marshall WL, Laws DR, Barbaree HE, editors. Handbook of sexual assault: Issues, theories, and treatment of the offender. New York (NY): Plenum; 1989. pp. 143-159.

${ }^{4}$ Otto RK, Ogloff JRP. Defining forensic psychology. In Weiner IB, Otto RK, editors. Handbook of forensic psychology. 4th ed. Hoboken (NJ): Wiley; 2014. pp. 35-55.

${ }^{5}$ Australian Psychological Society: Forensic psychology [internet]. Melbourne (Australia): Australian Psychological Society; c.2016 [cited 2016 August 20] Available from: https://www.psychology.org.au/public/forensic/

${ }^{6}$ Andrews DA, Bonta J. The psychology of criminal conduct. 5th ed. New Providence (NJ): LexisNexis; 2010.

${ }^{7}$ Mills JF, Kroner DG, Morgan RD. Clinician's guide to violence risk assessment. London (UK): Guilford. 2011.

${ }^{8}$ Douglas KS, Hart SD, Groscup JL, Litwack TR. Assessing violence risk. In Weiner IB, Otto, RK, editors. Handbook of forensic psychology. 4th ed. Hoboken (NJ): Wiley; 2014. pp. 385-441.

${ }^{9}$ Conroy MA, Murrie DC. Forensic assessment of violence risk. New York (NY); Wiley. 2007.

${ }^{10}$ Tamatea A. The problem with 'the problem with gangs': Reflections on practice and offender desistance. Practice: The New Zealand Corrections Journal. 2015;3(1): 33-36.

${ }^{11}$ Boer DP, Hart SD, Kropp PR, Webster CD. Manual for the Sexual Violence Risk-20: Professional guidelines for assessing risk of sexual violence. Vancouver (Canada): Mental Health, Law, and Policy Institute; 1997.

${ }^{12}$ Kropp PR, Hart SD, Webster CD, Eaves D. Spousal Assault Risk Assessment guide (SARA). Toronto (Canada): Multi-Health Systems; 1999.

${ }^{13}$ Wong SCP, Gordon A. Violence Risk Scale manual. Saskatchewan (Canada); 2000.

${ }^{14}$ Douglas KS, Webster CD, Hart SD, Eaves D, Ogloff JRP. HCR-20: Violence risk management companion guide. Burnaby (Canada): Mental Health, Law, and Policy Institute, Simon Fraser University; 2001.

${ }^{15}$ Douglas KS, Hart SD, Webster CD, Belfrage H. HCR-20v3: Assessing risk for violence - User guide. Burnaby (Canada): Mental Health, Law, and Policy Institute, Simon Fraser University; 2013.

${ }^{16}$ Serin RC. The Dynamic Risk Assessment for Offender Re-entry (DRAOR). Unpublished user manual. Ottawa (Canada): Carelton University; 2007.

${ }^{17}$ Tamatea A, Wilson N. Dynamic risk assessment for offender re-entry (DRAOR): A pilot study. Unpublished government report. Wellington (NZ): Department of Corrections; 2009.

${ }^{18}$ de Vogel V, de Ruiter C, Bouman Y, de Vries Robbé M. SAPROF: Guidelines for the assessment of protective factors for violence risk. Utrecht (The Netherlands): Forum Educatief; 2009.

${ }^{19}$ Webber C. Background, foreground, foresight: The third dimension of cultural criminology? Crime Media Culture. 2007;3(2): 139-157.

${ }^{20}$ Ferrell J. Cultural criminology. Annual Review of Sociology. 1999;25: 395-418.

${ }^{21}$ Ferrell J. Cultural criminology and the politics of meaning. Critical Criminology. 2013;21:257-271.

${ }^{22}$ Atkinson DR, Morten G, Sue DW. Counseling American minorities. Boston (MA): McGraw Hill; 1998. 


\author{
Australian Journal of Forensic Sciences
}

${ }^{23}$ Wilson H, Gutierrez L. A meta-analysis examining the predictive ability of the level of service inventory (LSI) with aboriginal offenders. Criminal Justice and Behavior, 2014;41(2):196-219.

${ }^{24}$ López SR, Guarnaccia PJ. Cultural psychopathology: Uncovering the social world of mental illness. Annual Review of Psychology. 2000;51(1):571-598.

${ }^{25}$ Evans IM. Behavior therapy: Regulation by self, by others, and by the physical world. In O'Donnell $\mathrm{CR}$, Yamauchi LA, editors. Culture \& context in human behavior change: Theory, research, and applications. New York (NY): Peter Lang; 2005. pp. 13-39.

${ }^{26}$ Kleinman A. Rethinking psychiatry: From cultural category to personal experience. New York (NY): Free Press; 1988.

${ }^{27}$ Ewert v. Canada 2015 FC 1093.

${ }^{28}$ Hanson RK. Morton-Bourgon K. The accuracy of recidivism risk assessments for sexual offenders: A meta-analysis of 118 prediction studies. Psychological Assessment. 2009;21(1):1-21.

${ }^{29}$ Långström N. Accuracy of actuarial procedures for assessment of sexual offender recidivism risk may vary across ethnicity. Sexual Abuse: A Journal of Research \& Treatment. 2004;16(2):107120.

${ }^{30}$ Allan A, Dawson D. Developing a unique risk of violence tool for Australian Indigenous offenders. CRC 6/00-01. Canberra (Australia): Criminology Research Council; 2006.

${ }^{31}$ Smallbone S, Rallings M. Short-term predictive validity of the Static-99 and Static-99-R for indigenous and non-indigenous Australian sexual offenders. Sexual Abuse. 2013;25(3):302316.

${ }^{32}$ Babchishin KM, Blais J, Helmus L. Do static risk factors predict differently for Aboriginal sex offenders? A Multi-Site Comparison using the Original and Revised Static-99 and Static-2002 Scales. Canadian Journal of Criminology and Criminal Justice. 2012;54:1-43.

${ }^{33}$ Day A. Reducing the risk of re-offending in Australian indigenous offenders: What works for whom? Journal of Offender Rehabilitation. 2003;37(2):1-15.

${ }^{34}$ Hsu C, Caputi P, Byrne MK. Level of Service Inventory-Revised: Assessing the risk and need characteristics of Australian indigenous offenders. Psychiatry, Psychology and Law. 2010;17(3):355-367.

${ }^{35}$ Case S. Young people 'at risk' of what? Challenging risk-focused early intervention as crime prevention. Youth Justice. 2006;6(3):171-179.

${ }^{36}$ Société canadienne de psychologie. Canadian code of ethics for psychologists. Ottawa (ON): Author; 2000.

${ }^{37}$ Australian Psychological Society. Code of ethics. Melbourne (Australia): Author; 2007.

${ }^{38}$ New Zealand Psychological Society. Te Tikanga Matatika: Code of ethics for psychologists working in Aotearoa/New Zealand. Wellington (NZ): Author; 2002.

${ }^{39}$ Ethics Committee of the British Psychological Society. Code of ethics and conduct. Leicester (UK): Author; 2009.

${ }^{40}$ American Psychological Association. Ethical principles of psychologists and code of conduct. Washington, D.C.: Author; 2010.

${ }^{41}$ Australian Bureau of Statistics: Aboriginal and Torres Strait Islander prisoner characteristics [Internet]. Belconnen (Australia): Australian Bureau of Statistics; 10 Dec 2015 [cited 2016 Aug 20]. Available from: http://www.abs.gov.au/

${ }^{42}$ Australian Bureau of Statistics: Estimates of Aboriginal and Torres Strait Islander Australians, June 2011 [Internet]. Belconnen (Australia): Australian Bureau of Statistics; 27 Jan 2016 [cited 2016 Aug 20]. Available from: http://www.abs.gov.au/

${ }^{43}$ Department of Corrections: Prison facts and statistics - March 2016 [Internet]. Wellington (NZ): Department of Corrections; 31 Mar 2016 [cited 2016 Aug 20]. Available from: http://www.corrections.govt.nz/

${ }^{44}$ Statistics NZ: Maori population estimates: Mean year ended 31 December 2015 [Internet]. Wellington (NZ): Statistics NZ; 16 May 2016 [cited 2016 Aug 20]. Available from: http://www.stats.govt.nz/

${ }^{45}$ Ministry of Health. He Pa Harakeke: Maori Health Workforce Profile: Selected regulated health occupations 2007. Wellington (NZ): Ministry of Health; 2007.

${ }^{46}$ Australian Indigenous Psychologists Association. About AIPA [internet]. Australia: Australian Indigenous Psychologists Association; c.2016 [cited 2016 August 20] Available from: http://www.indigenouspsychology.com.au/page/2970/about-aipa

${ }^{47}$ Sue DW, Sue D. Counseling the culturally different: Theory and practice. 2nd ed. New York (NY): Wiley; 1990. 


\author{
Australian Journal of Forensic Sciences
}

${ }^{48}$ Janus E. Failure to protect: America's sexual predator laws and the risk of the preventive state. Ithaca (NY): Cornell University Press; 2006.

${ }^{49}$ Trimble JE, Fisher CB. Introduction: Our shared journey: Lessons from the past to protect the future. In Trimble JE, Fisher CB, editors. Handbook of ethical research with ethnocultural populations and communities. Thousand Oaks (CA): Sage; 2006. pp. xv-xxix.

${ }^{50}$ Rack P. Culture, race, and mental disorder. London (UK): Tavistock; 1982.

${ }^{51}$ Sobo EJ. Culture and meaning in health services research: a practical field guide. Walnut Creek (CA): Left Coast Press; 2009.

${ }^{52}$ Sue DW, Sue D. Counseling the culturally diverse: Theory and practice. 6th ed. New York (NY): Wiley; 2013.

${ }^{53}$ Ellerby L. Community-based treatment of aboriginal sexual offenders: Facing realities and exploring possibilities. Forum on Corrections Research. 1994;6,23-25.

${ }^{54}$ Couture JE. Multicultural competence: Theory and practice for correctional psychologists. In Leis TA, Motiuk LL, Ogloff JRP, editors. Forensic psychology: Policy and practice in corrections. Canada: Correctional Service of Canada; 1995.

${ }^{55}$ Tamatea AJ, Ryan J, Mason P. Bicultural Therapy Model (BTM) Review. Wellington (NZ): Department of Corrections; 2009.

${ }^{56}$ Williams C. The too-hard basket: Maori and criminal justice since 1980. Wellington (NZ): Institute of Policy Studies; 2001.

${ }^{57}$ Lynch MJ, Stretesky PB, Long MA. Defining crime: A critique of the concept and its implication. New York (NY): Palgrave Macmillan; 2015.

${ }^{58}$ Foster KR, Huber PW. Judging science: Scientific knowledge and the Federal Courts. Cambridge (MA): MIT Press; 1997.

${ }^{59}$ Sue S. Science, ethnicity, and bias: Where have we gone wrong? American Psychologist. 1999;54(12):1070-1077.

${ }^{60}$ Madison DS. Critical ethnography: Method, ethics, and performance. Thousand Oaks (CA): Sage; 2012.

${ }^{61}$ Garrett HJ. The routing and re-routing of difficult knowledge: Social studies teachers encounter "when the levees broke". Theory and Research in Social Education. 2011;39(2):320-347.

${ }^{62}$ Halloran MJ. Indigenous reconciliation in Australia: Do values, identity and collective guilt matter? Journal of Community and Applied Social Psychology. 2007;17:1-18.

${ }^{63}$ Matthews RA. The construction of 'So What?' criminology: A realist analysis. Crime, Law \& Social Change. 2010;54:125-140.

${ }^{64}$ Quinsey LV, Harris TG, Rice EM, Cormier AC. Violent offenders: Appraising and managing risk. Washington DC: American Psychological Association; 1998. p. 171.

${ }^{65}$ Smallbone S, Rallings M. Short-term predictive validity of the Static-99 and Static-99-R for indigenous and non-indigenous Australian sexual offenders. Sexual Abuse. 2013;25(3):302316.

${ }^{66}$ Skelton A, Riley D, Wales D, Vess J. Assessing risk for sexual offenders in New Zealand: Development and validation of a computer-scored risk measure. Journal of Sexual Aggression. 2006;12(3):277-286.

${ }^{67}$ Groth-Marnat G. Handbook of psychological assessment, 5th ed. New York (NY): Wiley; 2009.

${ }^{68}$ Hanson RK, Morton-Bourgon K. The accuracy of recidivism risk assessments for sexual offenders: A meta-analysis of 118 prediction studies. Psychological Assessment. 2009;21(1):1-21.

${ }^{69}$ Rogers R. The uncritical acceptance of risk assessment in forensic practice. Law \& Human Behavior. 2000;24(5):595-605.

${ }^{70}$ Bonta J. Offender risk assessment: Guidelines for selection and use. Criminal Justice \& Behavior. 2002;29(4):355-379.

${ }^{71}$ Ward T, Marshall WL. Narrative identity and offender rehabilitation. International Journal of Offender Therapy \& Comparative Criminology. 2007;51(3):279-297.

${ }^{72}$ Bennett RR. Constructing cross-cultural theories in criminology: Application of the generative approach. Criminology. 1980;18(2):252-268. 